\title{
Implementation of Medical Assistance in Dying: An evaluation of clinician knowledge and perceptions at a large urban multi-site rehabilitation centre in Toronto
}

\author{
Stephanie Hogg, Pria Nippak, Karen Spalding \\ School of Health Services Management, Ted Rogers School of Management, Ryerson University, Toronto, Canada
}

Received: July 11, 2018

DOI: $10.5430 /$ jha.v7n5p41

\author{
Accepted: August 22, 2018 \\ Online Published: August 24, 2018 \\ URL: https://doi.org/10.5430/jha.v7n5p41
}

\begin{abstract}
Objective: Evaluate clinician knowledge and perceptions to ensure the newly implemented Medical Assistance in Dying (MAID) policies and guidelines are understood correctly to help facilitate the best possible experience for patients and their families. Methods: One hundred and twenty-five clinicians completed a survey, developed for this study, to determine their perceptions and knowledge base related to MAID.

Results: The average grade on the knowledge-based portion of the survey was $69 \%$. On average, respondents displayed a good understanding $(84 \%)$ of the legislated eligibility criteria while room for improvement was noted for facility specific policy questions $(65 \%)$ and general principle questions $(71 \%)$. Analysis of perception-based questions indicated most respondents were in support of MAID, however, they expressed mixed feelings towards the ease of having MAID related conversations. Respondents expressed mixed opinions in relation to whether the facility was providing adequate training to staff. Sixty-four percent of respondents expressed interest in receiving further training relating to MAID.

Conclusions: Education for healthcare providers to ensure they understand the relevant hospital policy and guidelines is critical to improve compliance with the implementation of MAID. It is important to continue to understand and support the perceptions of clinicians to ensure that MAID is administered correctly and as effectively as possible.
\end{abstract}

Key Words: Medical Assistance in Dying, Physicians assisted dying, Euthanasia

\section{INTRODUCTION}

Historically, the Criminal Code of Canada outlined that assisting a person in ending their own life was a crime punishable by law. However, on February 6, 2015 the Supreme Court of Canada released its ruling on the Carter v. Canada case which resulted in changes to the way Canada viewed Physician Assisted Dying. Physician Assisted Dying, now referred to as Medical Assistance in Dying (MAID), according to the College of Physicians and Surgeons of Ontario occurs when "a medical practitioner or nurse practitioner, at an individual's request: (1) administers a substance that causes an individual's death; or (2) prescribes a substance for an individual to self-administer to cause their own death". ${ }^{[1]}$ In summary, this ruling determined that the Criminal Code of Canada's prohibition on physicians assisting in the termination of life infringed upon a persons right to life, liberty and security, which consequently provides rationale for the decision. ${ }^{[2]}$ Given this change to the Criminal Code of Canada, there were major implications for all the provincial/territorial governments, since they are responsible for the delivery of

\footnotetext{
*Correspondence: Stephanie Hogg; Email: stephanie.hogg@hotmail.com; Address: School of Health Services Management, Ted Rogers School of Management, Ryerson University, Toronto, Canada.
} 
healthcare. Under tight deadlines, healthcare provider organizations were mandated to create policies and guidelines to oversee and implement MAID.

In an innovative internal report, Malina et al. outlined barriers encountered during the implementation of a MAID program at a Toronto based network of hospitals known as the University Health Network (UHN). ${ }^{[3]}$ The authors described conditions of ambiguity when UHN worked to ensure timely access to services while taking into consideration the legal rights of patients and healthcare providers during the implementation phase of MAID. ${ }^{[3]}$ In this report, the authors mention the importance of staff education as well as organizational culture surrounding MAID. ${ }^{[3]}$

Since MAID is now legal in Canada, organizations in each province and territory are attempting to develop policies and guidelines that adhere to ethical, legal and professional standards for both organizations and practitioners, while also trying to meet the needs of patients and families. Given the impact on practice due to this major change in legislation, it is imperative that the development and implementation of these new policies and guidelines are carefully evaluated. To ensure compliance while minimizing risk, it is crucial that proper policies are in place and executed effectively. As supported by a British Medical Association article, this objective is achieved by ensuring providers are educated and confident in executing these procedures. ${ }^{[4]}$

The following study sets out to assess clinician perceptions and knowledge surrounding the newly implemented organizational policies and guidelines to determine if they are understood correctly in order to help facilitate the best possible experience for patients and their families. Although similar studies exist originating from other countries experiences with euthanasia/MAID, this study is the first of its kind in Canada to evaluate clinician perceptions and knowledge to ensure the newly implemented policies and guidelines are understood correctly.

\section{MethodS}

The study was completed at a large urban multi-site rehabilitation centre in Toronto. The study took place primarily in the Complex Continuing Care Program. This program consists of five inpatient units including the: Low Tolerance Long Duration Rehabilitation Unit, Transitional Care Unit, and three complex continuing care units. These specialty areas are focused on caring for those patients who have complex medical conditions. This program specializes in managing patients' health conditions while aiming to improve their overall well-being and restoring their maximum level of independence.

\subsection{Design}

The study was a process evaluation that utilized a crosssectional approach with a prospective mixed method survey design.

\subsection{Sample}

The target population for this study was clinicians employed at the selected facility who worked primarily on one of the identified units in the Complex Continuing Care Program. The survey was completed by 125 out of 325 clinicians representing $38 \%$ of the total number of Registered Nurses (RN), Registered Practical Nurses (RPN), or other allied health professionals in the Complex Continuing Care Program. The allied health professional portion of the sample may include clinical nutritionists, occupational therapists, physiotherapists, respiratory therapists, social workers, spiritual care providers, etc.

\subsection{Instrument/Tool}

The evaluation tool for this project was a survey developed for this specific study. The evaluation tool consisted of 20 questions with the aim of addressing four key areas including (see Table 1):

- Clinician characteristics (Question 1 to 5)

- Knowledge of MAID (Question 6 to 17)

- Perceptions of MAID (Question 18 and 19)

- Questions, comments or feedback (Question 20)

Survey questions were either a multiple choice, True/False or Likert scale rating format to allow for easy comparison with the exception of the final open-ended question. All questions, excluding question 18 , were created by the authors based on a review of existing literature for the demographic/characteristics and perception based questions as well as a review of institution resources for the knowledgebased questions. Question 18 was adapted from an existing study with a similar objective of measuring nurses' attitudes towards euthanasia. ${ }^{[5]}$ Minor changes were made to specific terminology within the survey to better define or make the content relevant to Canadian legislation/concepts, for example, euthanasia was changed to MAID. All survey questions were reviewed with the facilities subject matter experts, including MAID Coordinator and program managers/directors, to ensure relevance and precision. During this review, it was recommended to eliminate any demographic questions beyond the existing five to avoid the possibility of identifying respondents which was determined to be factor that may negatively affect the number of responses received. The survey was also piloted at a separate facility by nursing staff and management to test for correctness, usefulness, and ease of understanding as a strategy to increase reliability of results.

ISSN 1927-6990 E-ISSN 1927-7008 
Following the pilot, adjustments were made to the order of survey instructions were simplified. survey questions, minor vocabulary modifications and the

Table 1. Knowledge based question results

\begin{tabular}{|c|c|c|c|c|c|}
\hline $\begin{array}{l}\text { Question } \\
\text { Category }\end{array}$ & $\begin{array}{l}\text { Survey } \\
\text { Question \# }\end{array}$ & Survey Question & Correct Response & $\begin{array}{l}\text { \# of Responses } \\
\text { (n) }\end{array}$ & $\begin{array}{l}\text { Average } \\
\text { Grade }\end{array}$ \\
\hline \multirow{5}{*}{ General } & 7 & $\begin{array}{l}\text { Medical Assistance in Dying (MAID) can be } \\
\text { defined as a physician or nurse practitioner, at an } \\
\text { individual's request: (1) administers a substance } \\
\text { that causes an individual's death; or (2) prescribes } \\
\text { a substance for an individual to self-administer to } \\
\text { cause their own death. }\end{array}$ & TRUE & 121 & $69 \%$ \\
\hline & 11 & $\begin{array}{l}\text { Patients can provide an advanced directive for } \\
\text { MAID through a living will and/or Power of } \\
\text { Attorney. }\end{array}$ & FALSE & 118 & $43 \%$ \\
\hline & 12 & $\begin{array}{l}\text { Consent for MAID may be withdrawn at any time } \\
\text { throughout the process and in any manner (verbal } \\
\text { or written)? }\end{array}$ & TRUE & 121 & $94 \%$ \\
\hline & 14 & $\begin{array}{l}\text { MAID is a substitute or replacement for excellent } \\
\text { symptom management at end of life. }\end{array}$ & FALSE & 121 & $79 \%$ \\
\hline & 8 & $\begin{array}{l}\text { MAID is a substitute or replacement for palliative } \\
\text { sedation at end of life. }\end{array}$ & FALSE & 119 & $69 \%$ \\
\hline \multirow{3}{*}{ Eligibility } & 15 & $\begin{array}{l}\text { Medical Assistance in Dying is available only to } \\
\text { adults ( } 18 \text { years of age or older). }\end{array}$ & TRUE & 120 & $81 \%$ \\
\hline & 16 & $\begin{array}{l}\text { To be eligible for MAID, patients must have a } \\
\text { diagnosed medical condition that is: }\end{array}$ & $\begin{array}{l}\text { All of the above } \\
\text { (incurable/irremediable, } \\
\text { causing intolerable physical } \\
\text { or psychological pain, and } \\
\text { leading to a reasonably } \\
\text { foreseeable death) }\end{array}$ & 121 & $89 \%$ \\
\hline & 10 & $\begin{array}{l}\text { Patient must be capable of providing informed } \\
\text { consent at which point(s)? }\end{array}$ & $\begin{array}{l}\text { Time of request and } \\
\text { intervention }\end{array}$ & 121 & $83 \%$ \\
\hline \multirow{4}{*}{$\begin{array}{l}\text { Facility } \\
\text { Specific }\end{array}$} & 6 & $\begin{array}{l}\text { Medical Assistance in Dying is now legal in } \\
\text { Canada and available at this facility }\end{array}$ & TRUE & 122 & $95 \%$ \\
\hline & 9 & $\begin{array}{l}\text { Clinical staff are expected to participate in } \\
\text { respectful discussions about MAID when } \\
\text { requested by patients. }\end{array}$ & TRUE & 121 & $73 \%$ \\
\hline & 13 & $\begin{array}{l}\text { Clinical staff are not required to participate in the } \\
\text { assessment or intervention of MAID. }\end{array}$ & TRUE & 118 & $59 \%$ \\
\hline & 17 & $\begin{array}{l}\text { According to hospital policy, a___ day } \\
\text { mandatory reflection period begins from } \\
\text { the date of patients written request until MAID } \\
\text { intervention date. }\end{array}$ & 10 & 116 & $31 \%$ \\
\hline
\end{tabular}

\subsection{Procedure}

The survey was made available in an online and paper format. The paper based version was distributed across all nursing units in the Complex Continuing Care Program at the facility. One weekly visit over the course of three weeks was utilized to administer surveys on site. To ensure the sample was representative, the researcher visited the facility across all three shifts (days, evenings, and nights). Where possible, researcher presence was focused on heavily populated clin- ician areas such as break rooms, nursing stations and team huddles. A secure box was also placed on the nursing unit for clinicians to complete surveys in the researcher's absence. An online link to the same survey was made available to clinicians who preferred to complete the survey on their own time. The link was active throughout the same three-week timeline that the paper based survey was administered. The online survey, using Survey Monkey, was distributed by unit managers to their team via email. To eliminate the poten- 
tial for duplicate responses, instructions were included with the survey stating that only one questionnaire format (paper based or online) needed to be answered, as it was the same survey in different formats.

\subsection{Analysis}

All data collected was manually inputted into an Excel spreadsheet. At the end of the three-week data collection period, a descriptive analysis was performed including calculation of the absolute and relative frequencies of the responses. The knowledge based questions were divided into three categories to achieve a better understanding of knowledge gaps. Knowledge based questions were compared against an answer key to calculate grades for each participant. To provide a more in-depth analysis, averages were calculated for each individual question. Perception based questions were analyzed in percentages and frequencies for easy comparison within the Likert scale. Responses to the open-ended question were compiled in one document then reviewed by the researcher and team members to illicit themes that emerged from these comments.

\section{RESUltS}

The overall survey completion rate for all 125 responses was $95 \%$. The results will be reported in the same order that was used in the survey structure and include the following categories: participant characteristics, knowledge, perceptions, open ended.

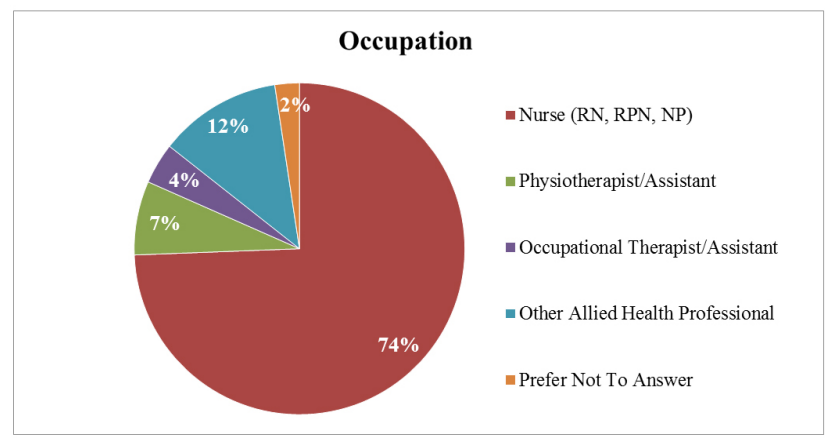

Figure 1. Respondent characteristics - occupation. This figure illustrates the study participant's current occupation

\subsection{Participant characteristic}

Analysis of participant characteristics showed that the majority of respondents were nurses $(74 \%)$ while the remaining respondents were allied health professionals $(24 \%)$ or selected "prefer not to answer" (2\%) (see Figure 1). Of this sample, the highest level of education completed by participants varied, however, $70 \%$ of study participants held a Bachelor's degree or higher (see Figure 2). In relation to years of clinical experience, 54\% of the study sample had 11 years or more of on the job experience (see Figure 3).

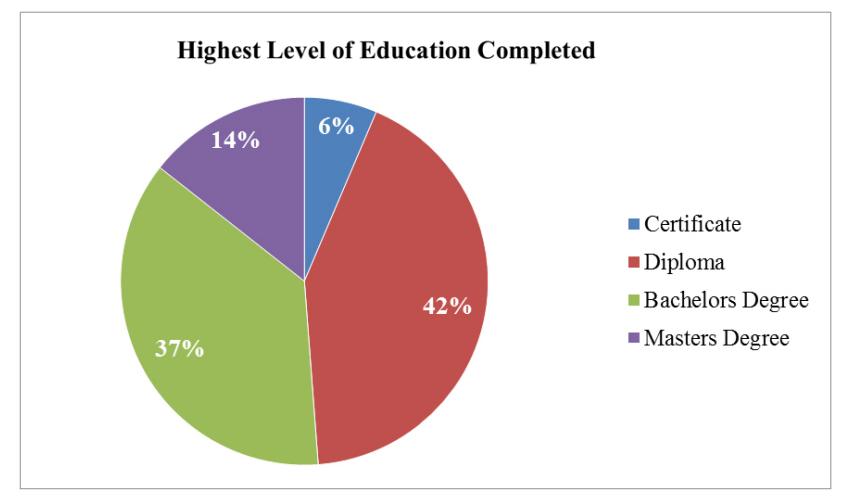

Figure 2. Respondent characteristics - education. This figure illustrates the study participants highest level of education completed

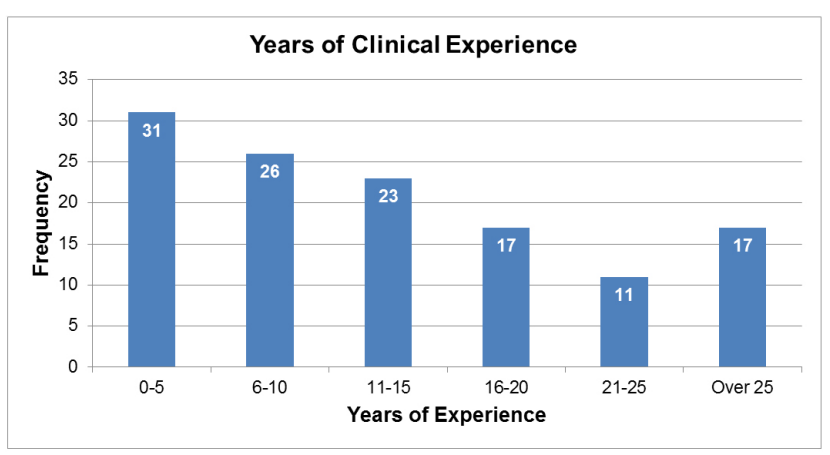

Figure 3. Respondent characteristics - years of clinical experience. This figure illustrates the study participants years of clinical experience

\subsection{Knowledge based questions}

The average grade on the knowledge based portion of the survey was $69 \%$. The majority of participants scored between $58 \%$ and $83 \%$ (see Figure 4). To better organize and manage the results all knowledge based questions were divided into three categories: general principles, eligibility criteria and facility specific policy. Upon investigation, the lowest average scores $(65 \%)$ were observed on survey questions relating to facility specific policy. In this category the lowest score $(31 \%)$ was in response to the question "According to policy, a ___ day mandatory reflection period begins from the date of patients written request until MAID intervention date", where only 36 participants correctly identified the answer of 10 days. The highest average scores (84\%) were achieved on survey questions relating to eligibility criteria. The remaining category of general principles revealed an average score of $71 \%$. The lowest score (43\%) was in response to the question "patients can provide an advanced directive 
for MAID through a living will and/or Power of Attorney", where only 51 participants correctly answered the question as false. Average grade scores were consistent showing minimal differences among clinicians when comparing grade scores with professional background and years of clinical experience. However, differences in the average grade scored were noted during comparison with the clinician's level of education. Specifically, the highest scores were achieved by clinicians holding a Bachelor or Master degree whereas the majority of lower scores were attained by clinicians with Certificates.

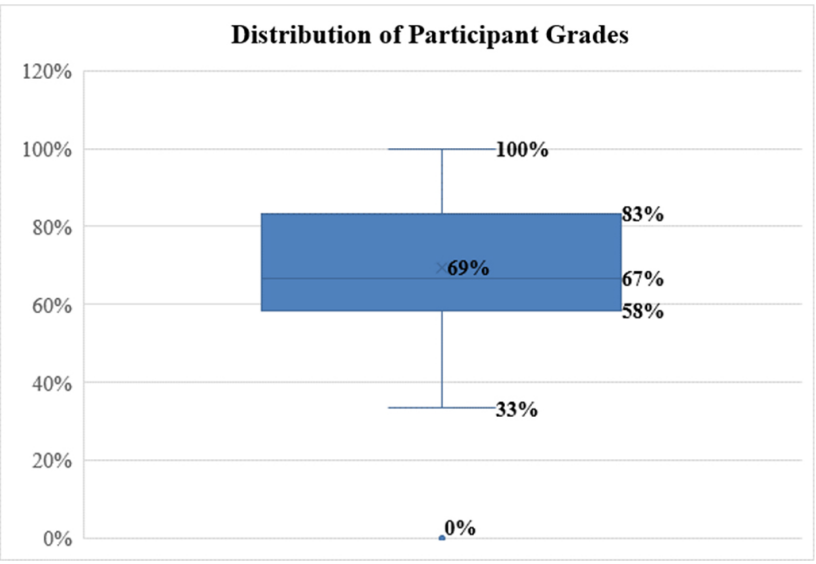

Figure 4. Distribution of Participant Grades. This figure illustrates the distribution of participants grades in relation to knowledge based survey questions

\subsection{Perception based questions}

For analysis purposes, the responses to perception based questions were combined into the following three categories: disagree (disagree and strongly disagree), neutral, and agree (agree and strongly agree). The first perception based question included principles of general acceptability relating to MAID (see Figure 5). This question yielded two results: most respondents are in support of MAID and respondents expressed mixed feelings when it comes to ease of having MAID related conversations. The first result is supported through analysis of questions related to clinician's attitudes towards MAID. For example, $74 \%$ of respondents accept MAID as a part of Canadian healthcare while 59\% agree that Canadians will benefit from its legalization. Furthermore, $70 \%$ of respondents believe MAID is a humane way to help patients who meet eligibility criteria while $82 \%$ agree that a patient should have the right to decide on his or her own death. Secondly, analysis of questions relating to clinician level of comfort and competency reinforced that respondents had mixed feelings when asked about their level of ease in having MAID related conversations. Specifically, when asked to rank the statement "I find it easy to discuss MAID", $44 \%$ of respondents disagree, $33 \%$ agreed while the remaining $23 \%$ remained neutral. Similarly, when asked to rank the statement "I have enough information on MAID to take part in discussion on the topic", $44 \%$ of respondents disagree, $33 \%$ agreed while the remaining $23 \%$ were neutral.

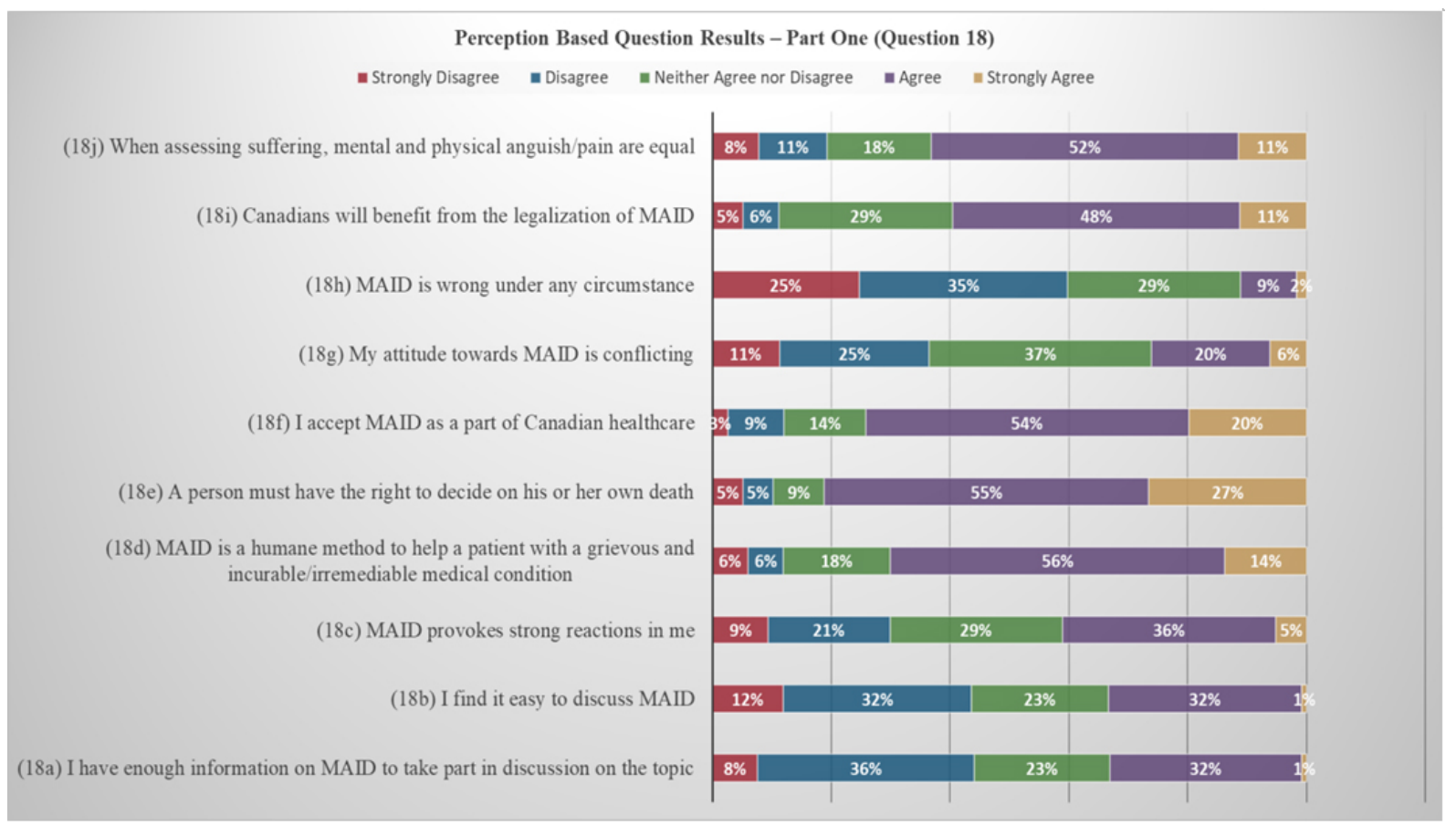

Figure 5. Perception Based Question Results (Question 18). This figure illustrates the percentage of responses for likert scale statements relating to principles of general acceptability of MAID 
The second perception based question asked respondents to rank facility specific statements that reflected their level of comfort and competency with MAID at the institution (see Figure 6). Respondents expressed mixed reviews in response to the statement that the facility has provided adequate training to staff. Specifically, $34 \%$ of study participants disagreed with the statement "the facility has provided adequate training relating to MAID" while $39 \%$ agreed. In relation to availability of educational resources for staff and patients/families, the majority of respondents agreed or held no strong opinion that the existing materials are effective. Sixty-four percent of respondents answered in agreement when asked if they were interested in additional training relating to MAID. Approximately $50 \%$ of respondents felt unprepared to deal with patient and family requests and questions relating to MAID compared to approximately $25 \%$ of respondents who felt they possessed enough information. Lastly, $49 \%$ of the respondents agreed they were familiar with whom to contact for more information or support relating to MAID.

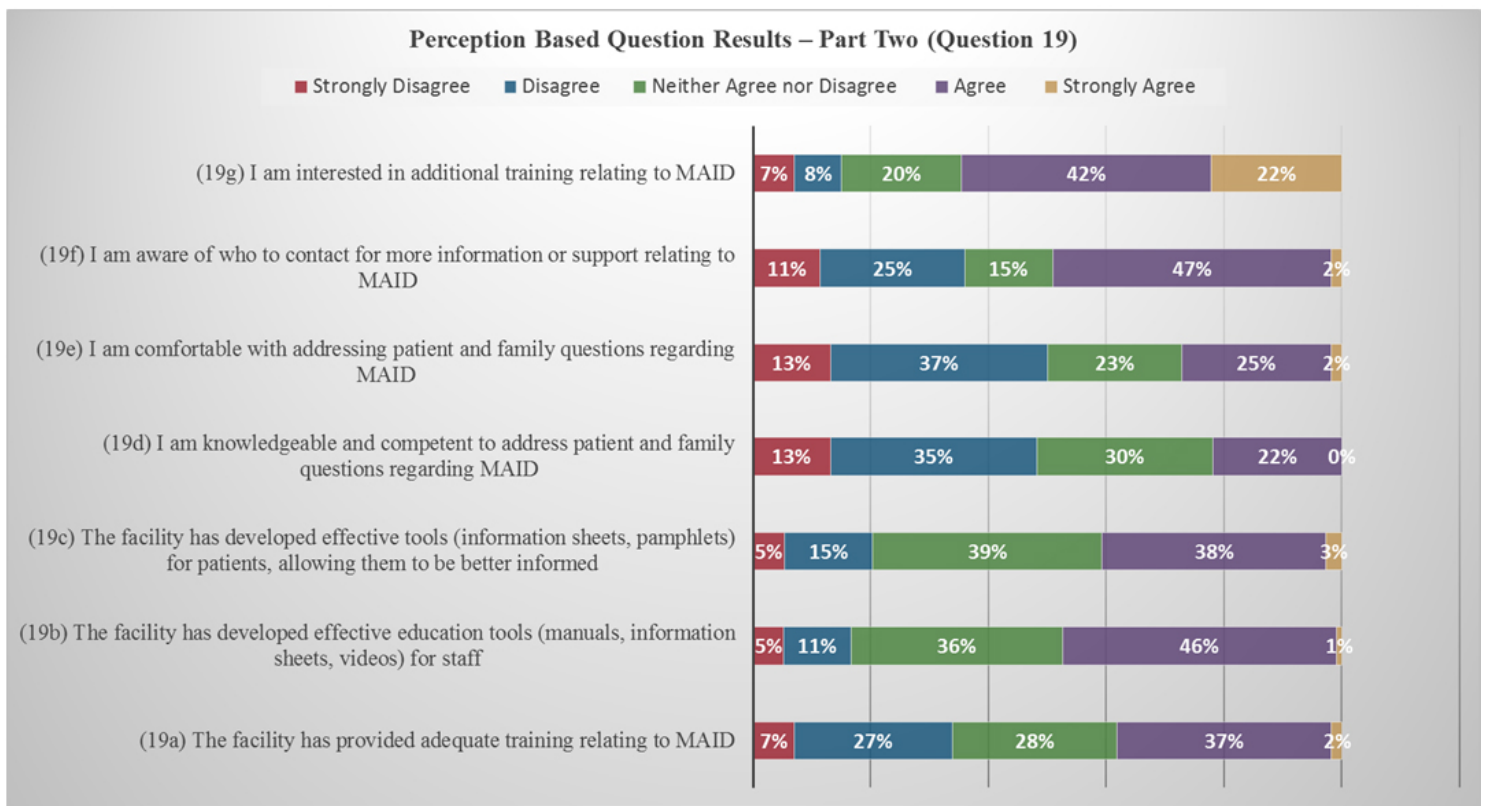

Figure 6. Perception Based Question Results (Question 19). This figure illustrates the percentage of responses for likert scale questions relating to clinician level of comfort and competency with MAID

\subsection{Open ended question}

The single open-ended question read, "Do you have any other comments, questions or feedback relating to the implementation of MAID?" There were sixteen responses or a twelve percent response rate received to this question. All responses shared a common theme that was related to education. Specifically, all sixteen participants expressed interest in further education on MAID. Examples of comments included "staff in service would be a great idea", "need a pamphlet on all units...", "Need more training regarding MAID - scenario training/practice", etc.

\section{Discussion}

The overall results of the survey administered in this study indicate that the clinicians do not have sufficient knowledge relating to MAID. Specifically, most of the clinicians surveyed expressed a lack of knowledge, leaving them feeling unprepared to handle conversations relating to MAID. This critical finding is consistent with previous research studies suggesting that this is a common concern amongst healthcare providers. ${ }^{[6,7]}$ The average grade resulting from the current study's knowledge based questions was slightly lower than expected at $69 \%$. In consultation with the facility, the target average grade was set at $85 \%-90 \%$ making the variance $16 \%-20 \%$. Although a seemingly high goal, this organization takes pride in being a leader in MAID and therefore holds their staff to a high standard. The study results do not highlight any one category that was significantly lacking knowledge, however, the results helped highlight the main topics where clinicians scored lower than anticipated. These low scoring questions represent a knowledge gap and identify areas for improvement.

Similar to previous studies, the clinicians surveyed expressed a high rate of acceptance in regards to the legalization of MAID. ${ }^{[8,9]}$ The results from this study, in support of earlier research, indicate that clinicians express a higher accep- 
tance of MAID in general, compared to their actual intent and readiness to be involved with this intervention. ${ }^{[10,11]}$ Specific concerns became apparent in relation to perceived level of competency and comfort while addressing patient or family questions relating to MAID. The importance of effective communication is well established in healthcare literature; however, Marcus \& Mott suggest there are little to no resources available to explain how to approach these conversations. ${ }^{[12]}$ The authors go on to mention that although difficult conversations may cause distress to patients and their families, these conversations also provide an opportunity to positively change a patients perception. ${ }^{[12]}$

Coinciding with findings of a previous study, ${ }^{[13]}$ the results of this study support the commonality that some providers have intense emotions and conflicting personal opinions surrounding MAID. Otte et al. ${ }^{[14]}$ outline three common themes expressed by providers who do not support MAID including: psychological impact on provider, religious beliefs/moral values, and professional role. Nevertheless, Canadian legislation provides room for conscientious objection among clinicians, which therefore exempts the portion of clinicians who do not support MAID from participating in interventions. This concept is important as a clinician's professional attitude may hold the power to encourage or discourage a patient from pursing this intervention. ${ }^{[15]}$ Conscientious objection is an important way of respecting and supporting clinician's individual beliefs so they feel comfortable providing their patients information and resources in a respectful and compassionate way. As reinforced by a Canadian Medical Association Journal article, the overriding of conscientious objection is not only damaging to the medical profession, but not required in upholding the patient's right of access to MAID. ${ }^{[16]}$ The article adds that forcing a clinician to participate in MAID or to refer to a willing counterpart may leave the clinician feeling "reluctant, [thus] leaving vulnerable patients and their caregivers fighting their own doctor for their rights". ${ }^{[16]}$

Surveyed clinicians are seemingly aware of current educational tools for both staff and patients however, there does appear to be room for improvement. A closer examination of the results indicates that approximately half of the clinicians surveyed are not aware of who to contact for more information or support regarding MAID. This crucial finding speaks to the importance of educating clinicians on who to contact or where to access further information to eliminate misinformation being conveyed to patients and their families. Providing healthcare providers with the appropriate contacts will support the effective delivery and adherence to MAID policy and guidelines. The study results show the clinicians are eager to increase training opportunities relating to MAID.
As reinforced by a post program implementation review, it is very important to develop educational programs for care providers to ensure the legislation, policy and guidelines, and professional obligations are understood. ${ }^{[17]}$ A study testing the efficacy of a one-day informative conference on increasing medical students' knowledge of euthanasia and physician assisted suicide concluded that the participants were able to substantially improve their level of knowledge. ${ }^{[18]}$ The results of this study support the importance and value of increasing educational opportunities for clinicians. The current study indicates a strong desire amongst clinicians for continuing education in this area. The education may focus on increasing participants' knowledge about MAID policies and guidelines as well as enhancing skills in conducting these difficult conversations with patients and family members. This may help improve the level of comfort and confidence clinicians report when asked about their perceptions of handling patient or family requests for MAID. As indicated in a study concerning Canadian medical student's attitudes towards MAID, the continued exposure to education and training resulted in an increased level of comfort in discussing related matters as well as a more positive attitude towards the treatment. ${ }^{[19]}$ Similar findings were reported in a study about end-of-life conversations which proposed that clinician's attendance at a skills-based workshop positively correlated with increased knowledge and a change of attitude regarding this topic. ${ }^{[20]}$ Runkle et al. go on to suggest that with greater familiarity or mastery of subject material, clinicians express greater confidence and ease of having end-of-life conversations. ${ }^{[20]}$

\section{Limitations}

Overall, this study had few limitations. One limitation was the design focused solely on nursing staff and allied health professionals and therefore the opinions of other healthcare providers such as physicians were not accounted for in the current study. A second limitation of this study was the sample was taken from a site providing only rehabilitation services. One may argue these results may differ when compared to those on an acute care unit such as an intensive care or surgical unit potentially decreasing external validity. Another limitation is the study focused on defining clinicians' perceptions of MAID, but did not investigate how underlying beliefs or attitudes may impact their perceptions or execution of MAID. Addressing this impact may provide the opportunity to identify barriers and pave the way for future improvements to the MAID process. Lastly, the lack of prior research studies relating to knowledge levels of MAID proves difficult in comparability of results. Overall, the above limitations do not have a major impact on this study nevertheless provide an opportunity for future studies 
to expand the scope of this topic.

\section{Conclusions}

This study provides evidence of the impact the newly implemented legislation around MAID has on clinicians in a large urban multi-site rehabilitation centre in Toronto. A major outcome from this study is the importance of ongoing education for healthcare providers to ensure compliance with hospital policy and guidelines. With more knowledgeable staff who are confident in having these difficult conversations with patients and families, this could contribute to improving the experience for patients and their families which is a key goal of healthcare organizations. Through gaining an understanding of clinician's perceptions and level of comfort relating to MAID, facilities can use this knowledge to educate other clinicians, in turn contributing to the overall goal of successful implementation. Additionally, this study highlighted the importance of allowing and supporting conscientious objection. Conscientious objection allows clinicians who for whatever reason, do not agree with MAID to opt out of participating in the intervention.

Looking forward, future studies may wish to study factors that shape clinicians perceptions around MAID. In doing so, education can be targeted to specific ideologies to help reduce myths and ensure clinicians have the correct information. It may be worthwhile to conduct a study to test any differences in perception among clinicians with experience administering MAID versus clinicians who do not have hands on experience. If an effect is noted, it may be worthwhile to have an experienced clinician be a peer support or mentor for other clinicians who have not been directly exposed.

This study focused on the knowledge and perceptions of nurses and allied health professionals since these are the clinicians who provide the most hours of direct care and are therefore most likely to receive the initial request for MAID. ${ }^{[21,22]}$ Alternatively, future research may set out to evaluate physician's knowledge and perceptions related to MAID in order to highlight any differences. As a healthcare provider's role in MAID varies based on occupation, it would be valuable to compare the results of these two populations to determine if any similarities or differences exist so educational resources can be tailored to specific groups of healthcare providers.

Future studies may wish to conduct similar research across an entire organization to determine if clinician knowledge base and perceptions are influenced by the patient service the clinician primarily works on (i.e. medical, surgical, chronic care, etc.). Furthermore, a study may be conducted on a larger scale to assess for similarities and differences in clinicians knowledge and perceptions in different healthcare settings such as long-term care, chronic care, ambulatory care, or rural hospitals. In doing so, common gaps can be highlighted to determine specific areas where additional training can be focused to improve MAID policy across the healthcare system.

Lastly, future researchers may consider adjusting the survey to include scenario-based questions to explore the participants' understanding of the topic. This change is consistent with the feedback to the open ended question where clinicians highlight their desire for scenario based learning. Adding scenario based questions can further define knowledge gaps and provide material for scenario based education in the future. Researchers may add additional questions regarding participant demographics to further examine any effect these variables have on clinician knowledge and perceptions.

\section{Conflicts Of InTEREST Disclosure}

The authors declare they have no conflicts of interest.

\section{REFERENCES}

[1] The College of Physicians and Surgeons of Ontario. Medical Assistance in Dying. Retrieved September 12, 2017. Available from: http://www.cpso.on.ca/Policies-Publications/Po licy/Medical-Assistance-in-Dying

[2] Carter v. Canada (Attorney General), 2015 SCC 5, [2015] 1 S.C.R. 331. Date: 20150206.

[3] Malina D, Li M, Watt S, et al. Medical assistance in dying - implementing a hospital-based program in Canada. The New England Journal of Medicine. 2017; 376(21): 2082-2088. PMid: 28538128. https://doi.org/10.1056/NEJMms1700606

[4] Brannan S, Campbell R, Davies M, et al. BMA end-of-life care and physician-assisted dying project. Journal of Medical Ethics. 2016;
42(6): 409. PMid: 27222523. https://doi.org/10.1136/mede thics-2016-103608

[5] Terkamo-Moisio A, Kvist T, Kangasniemi M, et al. Nurses' attitudes towards euthanasia in conflict with professional ethical guidelines. Nursing Ethics. 2017; 24(1): 70-86. PMid: 27151310. https ://doi .org/10.1177/0969733016643861

[6] Gaston NR, Randall JM, Kiesel LR. Physician-assisted suicide and midwest social workers: Where do they stand? Journal of Social Work in End-of-Life \& Palliative Care. 2018; 14(1): 73. PMid: 29494791. https://doi.org/10.1080/15524256.2018.1433 097

[7] Kumaş G, Öztunç G, Nazan Alparslan Z. Intensive care unit nurses' opinions about euthanasia. Nursing Ethics. 2007; 14(5): 637-650. 
PMid: 17901174. https://doi.org/10.1177/096973300707 5889

[8] Inghelbrecht E, Bilsen J, Mortier F, et al. Attitudes of nurses towards euthanasia and towards their role in euthanasia: A nationwide study in flanders, belgium. International Journal of Nursing Studies. 2009; 46(9): 1209-1218. PMid: 19327772. https: //doi.org/10.1016/j.ijnurstu.2009.02.009

[9] Rousseau S, Turner S, Chochinov HM, et al. A national survey of canadian psychiatrists' attitudes toward medical assistance in death. The Canadian Journal of Psychiatry. 2017; 62(11): 787-794. PMid: 28548865. https://doi.org/10.1177/0706743717711174

[10] Zenz J, Tryba M, Zenz M. Palliative care professionals' willingness to perform euthanasia or physician assisted suicide. BMC Palliative Care. 2015; 14(1): 60. PMid: 26572742. https://doi.org/10.1 186/s12904-015-0058-3

[11] Miccinesi G, Fischer S, Paci E, et al. Physicians' attitudes towards end-of-life decisions: A comparison between seven countries. Social Science \& Medicine. 2005; 60(9): 1961-1974. PMid: 15743647. https://doi.org/10.1016/j.socscimed.2004.08.061

[12] Marcus JD, Mott FE. Difficult conversations: From diagnosis to death. The Ochsner Journal. 2014; 14(4): 712-717. PMid: 25598738. Available from: http://ezproxy.lib.ryerson.ca/login?u rl=https : //search-proquest-com.ezproxy.lib.ryerson .ca/docview/1640465039? accountid=13631

[13] Voorhees JR, Rietjens JAC, van der Heide A, et al. Discussing physician-assisted dying: Physicians' experiences in the united states and the netherlands. The Gerontologist. 2014; 54(5): 808-817. PMid: 24000266. https://doi.org/10.1093/geront/gnt087

[14] Otte IC, Jung C, Elger B, et al. "we need to talk!" barriers to GPs' communication about the option of physician-assisted suicide and their ethical implications: Results from a qualitative study. Medicine, Health Care, and Philosophy. 2017; 20(2): 249. PMid: 27785588. https://doi.org/10.1007/s11019-016-9744-z
[15] Dierckx de Casterlé B, Verpoort C, Bal ND, et al. Nurses' views on their involvement in euthanasia: A qualitative study in flanders (belgium). Journal of Medical Ethics. 2006; 32(4): 187-192. PMid: 16574869. https://doi.org/10.1136/jme. 2005.011783

[16] Fletcher J. Right to die in canada: Respecting the wishes of physician conscientious objectors. Canadian Medical Association Journal. 2005; 187(18): 1339. PMid: 26598370. https://doi.org/10.1 $503 / \mathrm{cmaj} .151238$

[17] Downie J. Medical assistance in dying: Lessons for australia from canada. QUT Law Review. 2017; 17(1): 127-146. https ://doi.or g/10.5204/qutlr.v17i2.721

[18] Muller MT, Onwuteaka-Philipsen BD, Kriegsman DM, et al. Voluntary active euthanasia and doctor-assisted suicide: Knowledge and attitudes of dutch medical students. Medical Education. 1996; 30(6): 428-433. PMid: 9217905. https://doi.org/10.1111/j.1365 $-2923.1996 . t b 00863 . x$

[19] Bator EX, Philpott B, Costa AP. This moral coil: A cross-sectional survey of canadian medical student attitudes toward medical assistance in dying. BMC Medical Ethics. 2017; 18(1). PMid: 29078769. https://doi.org/10.1186/s12910-017-0218-5

[20] Runkle C, Wu E, Wang EC, et al. Clinician confidence about conversations at the end of life is strengthened using the four habits approach. Journal of Psychosocial Oncology. 2008; 26(3): 81-95. PMid: 19042266. https://doi .org/10.1080/07347330802118040

[21] Francke A, Albers G, Bilsen J, et al. Nursing staff and euthanasia in the netherlands. A nation-wide survey on attitudes and involvement in decision making and the performance of euthanasia. Patient Education and Counselling. 2016; 99(5): 783-789. PMid: 26613667. https://doi.org/10.1016/j.pec.2015.11.008

[22] Van Bruchem-van de Scheur G, Van Der Arend A, Huijer Abu-Saad $\mathrm{H}$, et al. Euthanasia and assisted suicide in dutch hospitals: The role of nurses. Journal of Clinical Nursing. 2008; 17(12): 16181626. PMid: 18482123 . https://doi.org/10.1111/j.1365-2 $702.2007 .02145 . \mathrm{x}$ 